(2) Open Access Full Text Article

\title{
Intravitreal bevacizumab for delayed radiation maculopathy and papillopathy after irradiation for maxillary sinus cancer
}

This article was published in the following Dove Press journal:

Clinical Ophthalmology

29 August 201 I

Number of times this article has been viewed

\author{
Miki Gondo' \\ Tsutomu Sakai ${ }^{\prime}$ \\ Hiroshi Tsuneoka' \\ Chihiro Kanehira ${ }^{2}$ \\ 'Department of Ophthalmology, \\ Jikei University School of Medicine, \\ ${ }^{2}$ Division of Radiology, Jikei University \\ School of Medicine, Tokyo, Japan
}

\begin{abstract}
Background: The evaluation of intravitreal bevacizumab treatment for delayed radiation maculopathy and papillopathy after irradiation for maxillary sinus cancer.

Case report: A patient with radiation maculopathy and papillopathy was treated with intravitreal bevacizumab $(1.25 \mathrm{mg})$. Main outcome measures included fundus photography, angiography, and optical coherence tomography (OCT). Two weeks after intravitreal bevacizumab, visual acuity improved from 0.4 to 1.2 . Fundus examination revealed decreased disc swelling, peripapillary hemorrhage, and macular edema. OCT demonstrated complete resolution of serous retinal detachment. At the 12-month follow-up, there was no exudation recurrence. No ocular or systemic side effects were observed.

Conclusion: Intravitreal bevacizumab can be used to treat radiation maculopathy and papillopathy. Antivascular endothelial growth factor therapy may decrease tissue injury associated with radiation vasculopathy.
\end{abstract}

Keywords: bevacizumab, radiation, maculopathy, papillopathy

\section{Introduction}

Radiation maculopathy and papillopathy are complications after radiotherapy for intracranial, skull base, and paranasal sinus tumors. Macular edema and serous retinal detachment associated with radiation maculopathy may lead to severe visual loss. Although the natural history of radiation papillopathy may be more favorable than previously assumed, ${ }^{1}$ any cases associated with underlying vascular disorders are more likely to be aggressive ${ }^{2}$ and there is still no evidence-based treatment for radiation papillopathy. More recently, there have been isolated reports of intravitreal bevacizumab (Avastin ${ }^{\circledR}$; Genentech Inc, San Francisco, CA) for radiation optic neuropathy or maculopathy secondary to plaque radiotherapy. ${ }^{3-5}$ Here, a case of delayed radiation maculopathy and papillopathy secondary to irradiation for maxillary sinus cancer that was successfully treated with intravitreal bevacizumab is reported.

\section{Case report}

A 73-year-old male presented with acute decrease in vision in the left eye 6 years after irradiation therapy for maxillary sinus cancer. The patient had a history of irradiation with a dose of 50-55 Gy in 1.8-1.9 Gy fractions to the cancer without invasion into eye and orbit. Treatment was performed with an anterior and lateral pair of $45^{\circ}$ wedged beams. The patient had no diabetes mellitus or vascular disease. On presentation, his best-corrected visual acuity was $1.2 \mathrm{OD}$ and $0.4 \mathrm{OS}$. Ophthalmoscopy was normal in the right eye but showed optic disc swelling with peripapillary hemorrhage, retinal
Correspondence: Tsutomu Sakai, Department of Ophthalmology, Jikei University School of Medicine, 3-25-8 Nishishimbashi, Minato-ku,

Tokyo I05-846I, Japan

$\mathrm{Tel}+8$ I 33433 I I I | ext 358 |

Fax +8I 334331936

Email tstmski@jikei.ac.jp 
exudates, and intraretinal microangiopathy in the left eye (Figure 1A). The corresponding fluorescein angiogram (FA) revealed optic disc and macular edema, capillary nonperfusion, microaneurysms, and vascular leakage (Figure 1B). Optic coherence tomography (OCT) demonstrated serous retinal detachment (SRD) (Figure 1C).

The patient was suspected to have radiation maculopathy and papillopathy in the left eye. Intravitreal bevacizumab (1.25 mg in $0.05 \mathrm{~mL}$ ) was provided to reduce vascular hyperpermeability and intraretinal neovascularization. Two weeks after the administration, visual acuity improved to 20/20 with resolution of SRD. Two months after administration, a color photograph showed decreased optic disc swelling, hemorrhage, and exudates (Figure 2A). OCT demonstrated complete regression of SRD (Figure 2C). The corresponding FA revealed markedly reduced macular edema, decreased intraretinal microangiopathy, and vascular leakage (Figure 2B). These findings were maintained over 12 months and at the last follow-up (Figure 3A-C).

\section{Discussion}

Radiation-induced retinopathy, maculopathy, and papillopathy are serious complications of head and neck radiotherapy. Takeda et al have suggested that radiation dose and area irradiated are the most important factors in the development of radiation retinopathy. ${ }^{6}$ The results in that study showed that $8 / 14(57 \%)$ eyes that received 50 Gy or more, over $60 \%$ or more of the area of the retina, developed severe retinal complications. ${ }^{6}$ Parsons et al also indicated that, in the dose range 45-50 Gy, 8/15 (53\%) eyes studied developed retinopathy and there was an increased risk of injury among patients who received fractional doses of over $1.9 \mathrm{~Gy}^{7}$ Kim et al reported that $63 / 93(67.7 \%)$ patients who received 70 cobalt
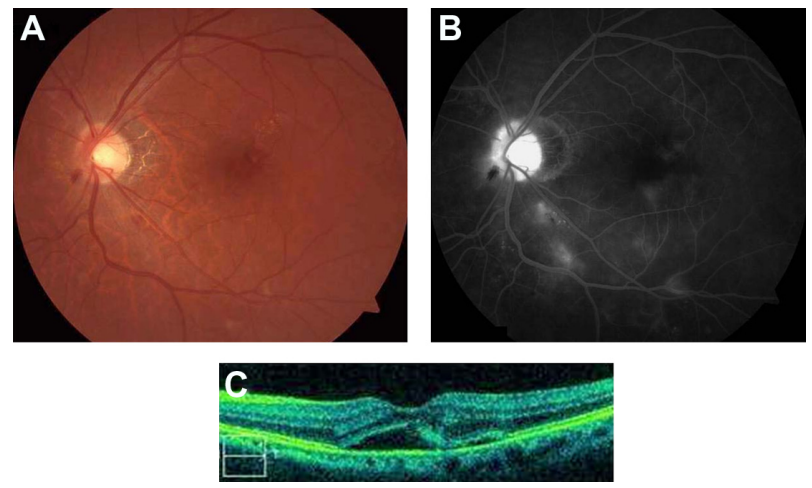

Figure I (A) Before bevacizumab treatment, the color fundus photograph shows optic disc swelling, peripapillary hemorrhage, retinal exudates and microangiopathy. (B) Fluorescein angiography demonstrates optic disc and macular edema, capillary nonperfusion, and microaneurysms. (C) Optical coherence tomography (OCT) reveals serous retinal detachment.
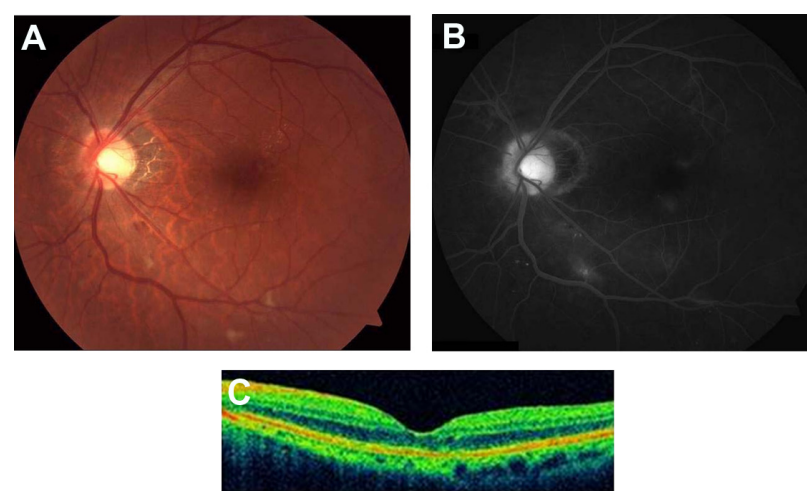

Figure 2 (A) Two months after treatment with intravitreal bevacizumab, the color fundus photograph shows a decrease of optic disc swelling, peripapillary hemorrhage, retinal exudates and microangiopathy. (B) Fluorescein angiography demonstrates improvement of optic disc and macular edema, and microaneurysms. (C) Optical coherence tomography (OCT) reveals complete resolution of serous retinal detachment.

Gy equivalents (CGEs) developed papillopathy a median of 1.5 years after irradiation. ${ }^{1}$ Demizu et al found that the maximum dose to the optic nerve $\left(>110 \mathrm{GyE}_{3}\right)$ was significant for the occurrence of radiation-induced optic neuropathy. ${ }^{8}$ Taking this into consideration, in this case with a dose of 50-55 Gy in 1.8-1.9 Gy fractions over $50 \%$ of the area of the retina, radiation damage to the macula and optic nerve might be mild and the clinical findings might support that view.

Intravitreal bevacizumab has been used in the treatment of age-related macular degeneration, ${ }^{9}$ retinal vein occlusion, ${ }^{10}$ and diabetic retinopathy ${ }^{11}$ as it inhibits the formation of abnormal blood vessels and reduces vascular hyperpermeability from vascular cell damage. Hopewell has noted that radiation injury in the central nervous system is a consequence of vascular rather than neural cell damage. ${ }^{12}$ Radiation papillopathy and maculopathy represent disc swelling, peripapillary hemorrhage, hard exudates, intraretinal
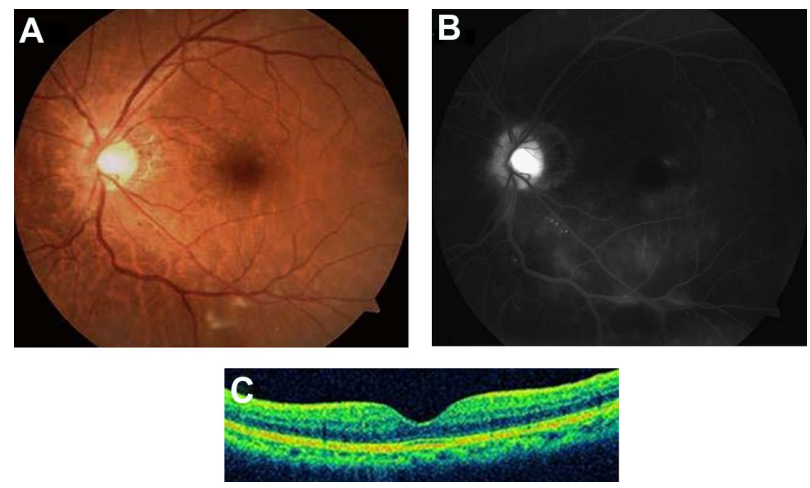

Figure 3 (A) Twelve months after treatment, the color fundus photograph shows a well-defined optic disc margin with resolution of peripapillary hemorrhage. (B) Fluorescein angiography demonstrates persistent decreased microangiopathy and vascular leakage. (C) Optical coherence tomography (OCT) reveals sustained resolution of serous retinal detachment. 
edema, subretinal fluid, and capillary nonperfusion by a radiation-damaged microvasculature. Thus, intravitreal bevacizumab may be a reasonable choice for radiation papillopathy and maculopathy, although the severe forms may need more aggressive therapy.

Rapid and sustained resolution of radiation maculopathy and papillopathy by intravitreal bevacizumab may be a consequence of prompt reduction of vascular hyperpermeability and prolonged suppression of retinal neovascularization. A recent study has shown that intravitreous ranibizumab (Lucentis $^{\circledR}$; Genentech, San Francisco, CA) can be used for radiation maculopathy. ${ }^{13}$ Because ranibizumab is in the form of smaller molecules with rapid wash-out, the drug may need repeated monthly injections and consequently increase the opportunity for adverse events such as endophthalmitis and retinal detachment. In addition, the costs of ranibizumab are much higher than bevacizumab. Therefore, the longer acting and less expensive bevacizumab therapy may be best for the treatment of radiation vasculopathy, although risk-benefit comparisons are still needed.

\section{Disclosure}

The authors report no conflicts of interest in this work.

\section{References}

1. Kim IK, Lane AM, Egan KM, Munzenrider J, Gragoudas ES. Natural history of radiation papillopathy after proton beam irradiation of parapapillary melanoma. Ophthalmology. 2010;117(8):1617-1622.
2. Gragoudas ES, Li W, Lane AM, Munzenrider J, Egan KM. Risk factors for radiation maculopathy and papillopathy after intraocular irradiation. Ophthalmology. 1999;106(8):1571-1577.

3. Finger PT. Anti-VEGF bevacizumab $\left(\right.$ Avastin $^{\circledR}$ ) for radiation optic neuropathy. Am J Ophthalmol. 2007;143(2):335-338.

4. Finger PT, Chin K. Anti-vascular endothelial growth factor bevacizumab (Avastin) for radiation retinopathy. Arch Ophthalmol. 2007; 125(6):751-756.

5. Gupta A, Muecke JS. Treatment of radiation maculopathy with intravitreal injection of bevacizumab (Avastin). Retina. 2008;28(7): 964-968.

6. Takeda A, Shigematsu N, Suzuki S, et al. Late retinal complications of radiation therapy for nasal and paranasal malignancies: relationship between irradiated-dose area and severity. Int J Radiat Oncol Biol Phys. 1999;44(3):599-605.

7. Parsons JT, Bova FJ, Fitzgerald CR, Mendenhall WM, Million RR. Radiation retinopathy after external-beam irradiation: Analysis of timedose factors. Int J Radiat Oncol Biol Phys. 1994;30(4):765-773.

8. Demizu Y, Murakami M, Miyawaki D, et al. Analysis of vision loss caused by radiation-induced optic neuropathy after particle therapy for head-and-neck and skull-base tumors adjacent to optic nerves. Int J Radiat Oncol Biol Phys. 2009;75(5):1487-1492.

9. Avery RL, Pieramici DJ, Rabena MD, Castellarin AA, Nasir MA, Giust MJ. Intravitreal bevacizumab (Avastin) for neovascular age-related macular degeneration. Ophthalmology. 2006;113(3): 363-372.

10. Iturralde D, Spaide RF, Meyerle CB, et al. Intravitreal bevacizumab (Avastin) treatment of macular edema in central retinal vein occlusion: a short-term study. Retina. 2006;26(3):279-284.

11. Haritoglou C, Kook D, Neubauer A, et al. Intravitreal bevacizumab (Avastin) therapy for persistent diffuse diabetic macular edema. Retina. 2006;26(9):999-1005.

12. Hopewell JW. Radiation injury to the central nervous system. Med Pediatr Oncol. 1998; Suppl 1:1-9.

13. Finger PT, Chin KJ. Intravitreous ranibizumab (Lucentis) for radiation maculopathy. Arch Ophthalmol. 2010;128(2):249-252.
Clinical Ophthalmology

\section{Publish your work in this journal}

Clinical Ophthalmology is an international, peer-reviewed journal covering all subspecialties within ophthalmology. Key topics include: Optometry; Visual science; Pharmacology and drug therapy in eye diseases; Basic Sciences; Primary and Secondary eye care; Patien Safety and Quality of Care Improvements. This journal is indexed on

Submit your manuscript here: http://www.dovepress.com/clinical-ophthalmology-journal

\section{Dovepress}

PubMed Central and CAS, and is the official journal of The Society of Clinical Ophthalmology (SCO). The manuscript management system is completely online and includes a very quick and fair peer-review system, which is all easy to use. Visit http://www.dovepress.com/ testimonials.php to read real quotes from published authors. 